\title{
Keamanan Sistem Perangkat Lunak dengan Secure Software Development Lifecycle
}

\author{
${ }^{1}$ Muhammad Rizky Hasan*, ${ }^{2}$ Suhermanto, ${ }^{3}$ Suharmanto \\ ${ }^{1,2}$ Magister Ilmu Komputer Universitas Budiluhur
}

\author{
Alamat Surat \\ Email: ${ }^{1}$ kesatrianagaapi@gmail.com, ${ }^{2}$ suher.yahmi@ gmail.com, \\ ${ }^{3}$ suharmanto.java@gmail.com \\ Article History: \\ Diajukan: 30-03-2021; Direvisi: 14-04-2021; Diterima: 28-04-2021
}

\begin{abstract}
ABSTRAK
Saat ini, pengembangan perangkat lunak lebih kompleks daripada sebelumnya di mana keamanan menjadi salah satu yang paling krusial. Masalah keamanan menjadi bagian penting untuk developer perangkat lunak.Kebutuhan keamanan dalam pengembangan perangkat lunak menghasilkanpenciptaan yang disebut Secure Software Development Life Cycle (SSDLC). Paper ini menyoroti kerentanan perangkat lunak dan pendekatan untuk mengatasinya. Untuk itu akan dibahas beberapa tool keamanan seperti OWASP dan ISSAF. Tujuannya agar dapat mengetahui sejauh mana tool-tool tersebut meminimalkan kerentanan dalam pengembangan perangkat lunak.
\end{abstract}

Kata Kunci : Keamanan; perangkat lunak; SSDLC

\section{ABSTRACT}

Software development is more complex than ever with security being one of the most crucial. Security issues are an important part for software developers. Security requirements in software development result in a creation called the Secure Software Development Life Cycle (SSDLC). This paper looks at software vulnerabilities and approaches to address them. For that we will discuss several security tools such as OWASP and ISSAF. The goal is to know the extent to which these tools minimize vulnerabilities in software development.

Keywords: Security; software; SSDLC

\section{INTRODUCTION}

Internet telah mengubah dunia, hari ini hampir semua orang yang terhubung ke Internet menunjukkan persentase penetrasi pengguna internet di dunia semakin meningkat. Kerentanan dari serangan dengan metode injeksi seperti Cross Site Scripting dan SQL Injection yang dapat digunakan oleh pihak tertentu untuk mencuri informasi atau untuk tujuan tertentu(Kurniawan, Riadi, \& Luthfi, 2017). Saat ini, pengembangan perangkat lunak lebih kompleks daripada sebelumnya di mana keamanan menjadi salah satu yang paling krusial. Masalah keamanan menjadi bagian penting untuk developer perangkat lunak dan memahami kerentanan, risiko dan lain-lain menjadi makanan sehari-hari(Fujdiak et al., 2019).

Kebutuhan keamanan dalam pengembangan perangkat lunak menghasilkanpenciptaan yang disebut Secure Software Development Life Cycle (SSDLC). Ini adalah konsep metodologis yang termasuk dalam Software Development Life Cycle, yang dijelaskan oleh limafase utama - analysis, design, implementation (building), testing, dan evaluation 
(deployment dan maintenance)(Fujdiak et al., 2019). Secure Software Development Life Cycle, SSDLC, menekankan pada keamanan ke dalam Software Development Life Cycle. Perangkat lunak yang aman tidak mudah dicapai dan ditunjukkan bahwa peningkatan proses pengembangan perangkat lunak dapat membantu meminimalkan jumlah kerentanan dalam pengembangan perangkat lunak. Namun, proses SSDLC melibatkan banyak praktik dan kegiatan keamanan untuk mencapai tujuan keamanan. Cara mengadopsi kegiatan ini dengan baik untuk meningkatkan keamanan perangkat lunak merupakan masalah yang penting(Tung, Lo, Shih, \& Lin, 2016).

Paper ini menyoroti kerentanan perangkat lunakdan pendekatan untuk mengatasinya. Untuk itu akan dibahas beberapa tool keamanan seperti OWASP dan ISSAF. Tujuannya agar dapat mengetahui sejauh mana tool-tool tersebut meminimalkan kerentanan dalam pengembangan perangkat lunak.

\section{RELATED WORKS}

Penyusunan paper ini mengambil beberapa referensi penelitian sebelumnya/jurnal-jurnal yang berhubungan dengan penelitian ini.

Tabel 1. Penelitan-Penelitian Sebelumnya

\begin{tabular}{|c|c|c|c|c|c|c|c|}
\hline $\begin{array}{l}\mathbf{N} \\
\mathbf{0 .}\end{array}$ & Judul & Penulis & $\begin{array}{l}\text { Jurnal/K } \\
\text { onferensi }\end{array}$ & $\begin{array}{l}\text { Tujuan } \\
\text { Penelitian }\end{array}$ & Masalah & Metode & $\begin{array}{l}\text { Hasil/Kesim } \\
\text { pulan }\end{array}$ \\
\hline 1. & $\begin{array}{l}\text { Forensic } \\
\text { Analysis } \\
\text { And } \\
\text { Prevent } \\
\text { Of Cross } \\
\text { Site } \\
\text { Scripting } \\
\text { In Single } \\
\text { Victim } \\
\text { Attack } \\
\text { Using } \\
\text { Open } \\
\text { Web } \\
\text { Applicat } \\
\text { ion } \\
\text { Security } \\
\text { Project } \\
\text { (Owasp) } \\
\text { Framew } \\
\text { ork }\end{array}$ & $\begin{array}{l}\text { Ade } \\
\text { Kurniawan, } \\
\text { Imam Riadi, } \\
\text { Ahmad } \\
\text { Luthfi }\end{array}$ & $\begin{array}{l}\text { Journal of } \\
\text { Theoretic } \\
\text { al and } \\
\text { Applied } \\
\text { Informati } \\
\text { on } \\
\text { Technolo } \\
\text { gy }\end{array}$ & $\begin{array}{l}\text { Menawark } \\
\text { an metode } \\
\text { proteksi } \\
\text { kepada } \\
\text { user }\end{array}$ & $\begin{array}{l}\text { Cyberatta } \\
\text { ck pada } \\
\text { individual } \\
\text { maupun } \\
\text { website } \\
\text { dengan } \\
\text { mengguna } \\
\text { kan } \\
\text { metode } \\
\text { cross site } \\
\text { scripting } \\
\text { atau sql } \\
\text { injection }\end{array}$ & $\begin{array}{l}\text { Open } \\
\text { Web } \\
\text { Applica } \\
\text { tion } \\
\text { Securit } \\
\text { y } \\
\text { Project } \\
\text { (OWA } \\
\text { SP) }\end{array}$ & $\begin{array}{l}\text { Forensic } \\
\text { Analysis } \\
\text { And Prevent } \\
\text { Of Cross } \\
\text { Site } \\
\text { Scripting In } \\
\text { Single } \\
\text { Victim } \\
\text { Attack } \\
\text { Using Open } \\
\text { Web } \\
\text { Application } \\
\text { Security } \\
\text { Project } \\
\text { (OWASP) } \\
\text { Framework } \\
\text { terbagi } \\
\text { menjadi } 3 \\
\text { tahap, yaitu: } \\
\text { Tahap } \\
\text { Attacking, } \\
\text { Tahap } \\
\text { Analisis, dan } \\
\text { Tahap } \\
\text { Patching. }\end{array}$ \\
\hline 2. & $\begin{array}{l}\text { DLR } \\
\text { Secure } \\
\text { Software } \\
\text { Engineer } \\
\text { ing }\end{array}$ & $\begin{array}{l}\text { Rohan } \\
\text { Krishnamurt } \\
\text { hy, Michael } \\
\text { Meinel, } \\
\text { Carina }\end{array}$ & $\begin{array}{l}2018 \\
\text { ACM/IEE } \\
\text { E 1st } \\
\text { Internatio } \\
\text { nal }\end{array}$ & $\begin{array}{l}\text { Meningk } \\
\text { atkan } \\
\text { software } \\
\text { develop } \\
\text { ment }\end{array}$ & $\begin{array}{l}\text { DLR adalah } \\
\text { sebuah } \\
\text { organisasi } \\
\text { penelitian } \\
\text { di Jerman }\end{array}$ & $\begin{array}{l}\text { DLR } \\
\text { Secure } \\
\text { Softwar } \\
\text { e } \\
\text { Engine }\end{array}$ & $\begin{array}{l}\text { Untuk } \\
\text { meningkatka } \\
\text { n proses } \\
\text { pengembang } \\
\text { an perangkat }\end{array}$ \\
\hline
\end{tabular}




\begin{tabular}{|c|c|c|c|c|c|c|c|}
\hline & & $\begin{array}{l}\text { Haupt, } \\
\text { Andreas } \\
\text { Schreiber, } \\
\text { Patrick } \\
\text { Mäder }\end{array}$ & $\begin{array}{l}\text { Workshop } \\
\text { on } \\
\text { Security } \\
\text { Awarenes } \\
\text { s from } \\
\text { Design to } \\
\text { Deployme } \\
\text { nt }\end{array}$ & $\begin{array}{l}\text { process } \\
\text { untuk } \\
\text { menghas } \\
\text { ilkan } \\
\text { software } \\
\text { berkeam } \\
\text { anan } \\
\text { tinggi }\end{array}$ & $\begin{array}{l}\text { yang } \\
\text { mengharusk } \\
\text { an untuk } \\
\text { membagika } \\
\mathrm{n} \text { atau } \\
\text { sharing } \\
\text { software } \\
\text { yang } \\
\text { mereka buat } \\
\text { kepada } \\
\text { partner dan } \\
\text { mempublik } \\
\text { asinya } \\
\text { secara } \\
\text { terbuka. } \\
\text { Karenanya } \\
\text { sangat } \\
\text { penting } \\
\text { sekali untuk } \\
\text { menguatkan } \\
\text { software } \\
\text { untuk } \\
\text { mencegah } \\
\text { penyeranga } \\
\text { n terbuka. }\end{array}$ & ering & $\begin{array}{l}\text { lunak, kami } \\
\text { memulai a } \\
\text { kelompok } \\
\text { penelitian } \\
\text { baru. Tujuan } \\
\text { kami adalah } \\
\text { untuk } \\
\text { mengoptima } \\
\text { lkan properti } \\
\text { proses } \\
\text { menggunaka } \\
\text { n } \\
\text { pendekatan } \\
\text { dari ilmu } \\
\text { data. Kami } \\
\text { menyertakan } \\
\text { dua sumber } \\
\text { utama data: } \\
\text { asal proses } \\
\text { perangkat } \\
\text { lunak dan } \\
\text { skor untuk } \\
\text { perangkat } \\
\text { lunak } \\
\text { keamanan } \\
\text { artefak itu. }\end{array}$ \\
\hline 3. & $\begin{array}{l}\text { An } \\
\text { Applicat } \\
\text { ion } \\
\text { Security } \\
\text { Framew } \\
\text { ork for } \\
\text { SOA- } \\
\text { based } \\
\text { Mission } \\
\text { Data } \\
\text { Systems }\end{array}$ & $\begin{array}{l}\text { Daniel } \\
\text { Fischer, } \\
\text { Mehran } \\
\text { Sarkarati, } \\
\text { Mariella } \\
\text { Spada, } \\
\text { Thomas } \\
\text { Michelbach, } \\
\text { Wenzel } \\
\text { Urban, } \\
\text { Christian } \\
\text { Tueffers }\end{array}$ & $\begin{array}{l}2011 \\
\text { Fourth } \\
\text { IEEE } \\
\text { Internatio } \\
\text { nal } \\
\text { Conferenc } \\
\text { e on } \\
\text { Space } \\
\text { Mission } \\
\text { Challenge } \\
\text { s for } \\
\text { Informati } \\
\text { on } \\
\text { Technolo } \\
\text { gy } \\
\text { 2011 } \\
\text { Space } \\
\text { Mission } \\
\text { Challenge } \\
\text { s for } \\
\text { Informati } \\
\text { on } \\
\text { Technolo } \\
\text { gy }\end{array}$ & $\begin{array}{l}\text { Menjelas } \\
\text { kan } \\
\text { sebuah } \\
\text { applicati } \\
\text { on } \\
\text { security } \\
\text { framewo } \\
\text { rk untuk } \\
\text { Sistem } \\
\text { data misi } \\
\text { berbasis } \\
\text { SOA } \\
\text { (Service } \\
\text { Oriented } \\
\text { Architect } \\
\text { ure) }\end{array}$ & $\begin{array}{l}\text { keamanan } \\
\text { informasi } \\
\text { adalah } \\
\text { bidang yang } \\
\text { semakin } \\
\text { berkemban } \\
\text { g dalam } \\
\text { ESA dan } \\
\text { badan } \\
\text { antariksa } \\
\text { lainnya. } \\
\text { Dalam } \\
\text { beberapa } \\
\text { tahun } \\
\text { terakhir, } \\
\text { ancaman } \\
\text { yang } \\
\text { dihasilkan } \\
\text { dari } \\
\text { kejahatan } \\
\text { dunia maya } \\
\text { telah } \\
\text { berkemban } \\
\text { g di seluruh }\end{array}$ & $\begin{array}{l}\text { Secure } \\
\text { Softwar } \\
\text { e } \\
\text { Develo } \\
\text { pment } \\
\text { Cycle } \\
\text { (SSDL } \\
\text { C) }\end{array}$ & $\begin{array}{l}\text { kami telah } \\
\text { mempresent } \\
\text { asikan } \\
\text { kerangka } \\
\text { kerja } \\
\text { keamanan } \\
\text { aplikasi } \\
\text { untuk } \\
\text { penyediaan } \\
\text { sistem data } \\
\text { misi SOA } \\
\text { yang mampu } \\
\text { meningkatka } \\
\text { n secara } \\
\text { signifikan } \\
\text { ketahanan } \\
\text { dan } \\
\text { keamanan } \\
\text { aplikasi } \\
\text { layanan } \\
\text { web. }\end{array}$ \\
\hline
\end{tabular}




\begin{tabular}{|c|c|c|c|c|c|c|c|}
\hline & & & & & dunia. & & \\
\hline 4. & $\begin{array}{l}\text { Managin } \\
\text { g the } \\
\text { Secure } \\
\text { Software } \\
\text { Develop } \\
\text { ment }\end{array}$ & $\begin{array}{l}\text { Radek } \\
\text { Fujdiak, Petr } \\
\text { Mlynek, } \\
\text { Pavel } \\
\text { Mrnustik, } \\
\text { Maros } \\
\text { Barabas, Petr } \\
\text { Blazek, Filip } \\
\text { Borcik, Jiri } \\
\text { Misurec. }\end{array}$ & $\begin{array}{l}2019 \text { 10th } \\
\text { IFIP } \\
\text { Internatio } \\
\text { nal } \\
\text { Conferenc } \\
\text { e on New } \\
\text { Technolo } \\
\text { gies, } \\
\text { Mobility } \\
\text { and } \\
\text { Security } \\
\text { (NTMS) }\end{array}$ & $\begin{array}{l}\text { fokus } \\
\text { pada } \\
\text { keamana } \\
\text { n SDLC } \\
\text { bersama } \\
\text { dengan } \\
\text { tantanga } \\
\text { n terkait } \\
\text { dan } \\
\text { masalah } \\
\text { terkait. }\end{array}$ & $\begin{array}{l}\text { Masalah } \\
\text { keamanan } \\
\text { menjadi } \\
\text { bagian } \\
\text { penting dari } \\
\text { Software } \\
\text { engineer } \\
\text { dan } \\
\text { memahami } \\
\text { kerentanan, } \\
\text { risiko, dan } \\
\text { lainnya } \\
\text { menjadi roti } \\
\text { sehari-hari. }\end{array}$ & SSDLC & $\begin{array}{l}\text { memperkena } \\
\text { lkanpendeka } \\
\text { tan, } \\
\text { menyoroti } \\
\text { tantangan, } \\
\text { dan } \\
\text { memunculka } \\
\text { n topik baru } \\
\text { pendekatan } \\
\text { manajemen } \\
\text { di SSDLC } \\
\text { bersama } \\
\text { dengan } \\
\text { pengenalan } \\
\text { alat } \\
\text { mSSDLC } \\
\text { kami }\end{array}$ \\
\hline 5. & $\begin{array}{l}\text { MENEN } \\
\text { TUKAN } \\
\text { DAMPA } \\
\text { K } \\
\text { RESIKO } \\
\text { KEAMA } \\
\text { NAN } \\
\text { BERBA } \\
\text { SIS } \\
\text { PENDE } \\
\text { KATAN } \\
\text { OWASP }\end{array}$ & $\begin{array}{l}\text { Robertus } \\
\text { Halomoan } \\
\text { Hutagalung, } \\
\text { Lukito Edi } \\
\text { Nugroho, } \\
\text { Risanuri } \\
\text { Hidayat }\end{array}$ & $\begin{array}{l}\text { Prosiding } \\
\text { SNATIF } \\
\text { Ke- } 4 \\
\text { Tahun } \\
2017\end{array}$ & $\begin{array}{l}\text { Asesmen } \\
\text { keamana } \\
\text { n pada } \\
\text { aplikasi } \\
\text { berbasis } \\
\text { website. }\end{array}$ & $\begin{array}{l}\text { Mengetahui } \\
\text { celah } \\
\text { keamanan } \\
\text { pada } \\
\text { aplikasi } \\
\text { berbasis } \\
\text { web saja } \\
\text { belum } \\
\text { cukup } \\
\text { untuk } \\
\text { meningkatk } \\
\text { an } \\
\text { keamanan } \\
\text { pada } \\
\text { aplikasi. }\end{array}$ & $\begin{array}{l}\text { Open } \\
\text { Web } \\
\text { Appliac } \\
\text { ation } \\
\text { Securit } \\
\text { y } \\
\text { Project }\end{array}$ & $\begin{array}{l}\text { Hasil } \\
\text { kemungkina } \\
\mathrm{n} \text { dan } \\
\text { dampak } \\
\text { keseluruhan } \\
\text { pada celah } \\
\text { local file } \\
\text { inclusion } \\
\text { adalah 6.375 } \\
\text { (High) pada } \\
\text { tingkat } \\
\text { overall } \\
\text { likelihood, 9 } \\
\text { (High) pada } \\
\text { tingkat } \\
\text { Overall } \\
\text { Technical } \\
\text { Impact, 4.75 } \\
\text { (Medium) } \\
\text { pada tingkat } \\
\text { Overall } \\
\text { Business } \\
\text { Impact. } \\
\text { Hasil } \\
\text { kemungkina } \\
\text { n dan } \\
\text { dampak } \\
\text { keseluruhan } \\
\text { pada celah } \\
\text { Sql } \\
\text { Injection }\end{array}$ \\
\hline
\end{tabular}




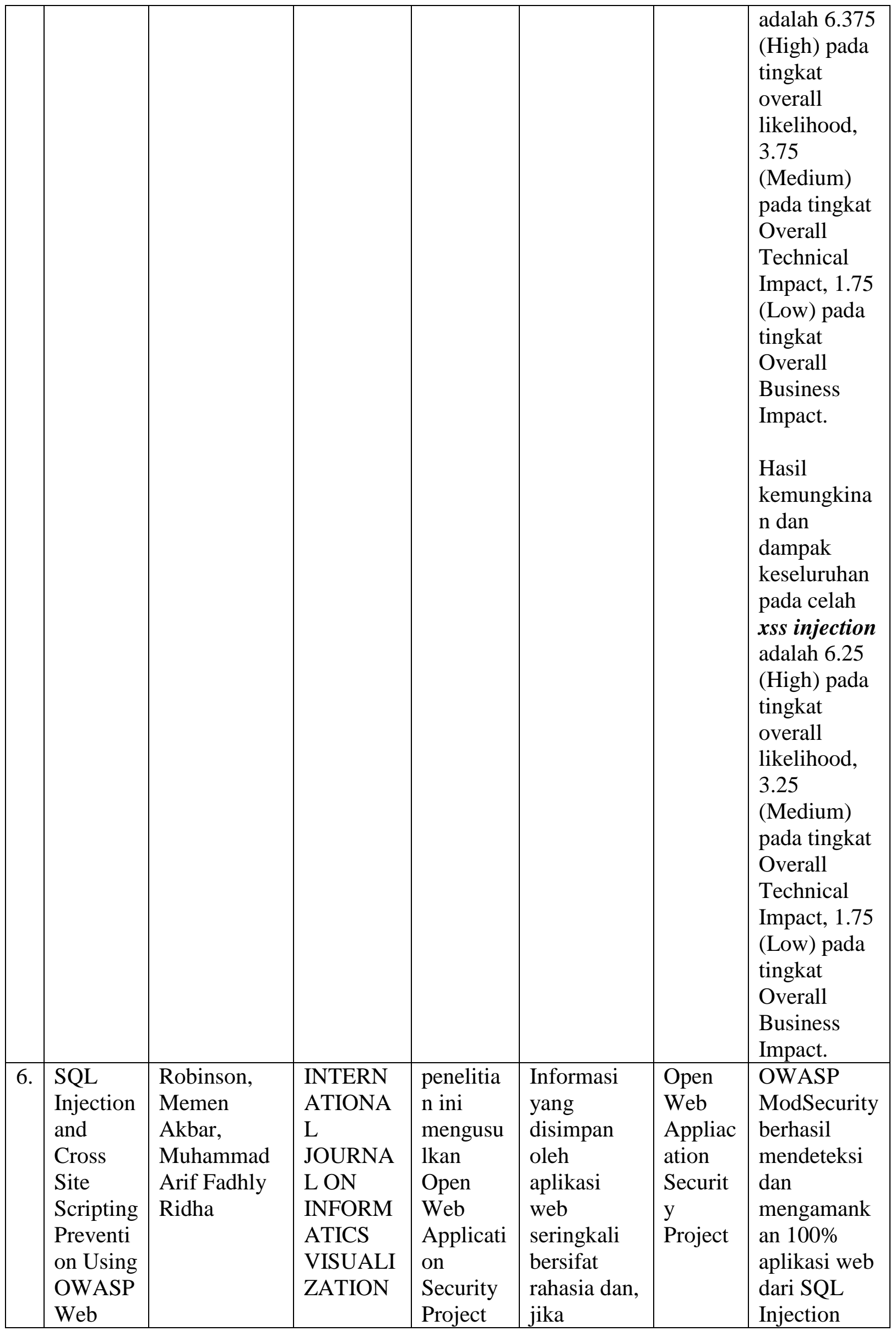




\begin{tabular}{|c|c|c|c|c|c|c|c|}
\hline & $\begin{array}{l}\text { Applicat } \\
\text { ion } \\
\text { Firewall }\end{array}$ & & & $\begin{array}{l}\text { (OWAS } \\
\text { P) } \\
\text { ModSec } \\
\text { urity } \\
\text { Core } \\
\text { Rule Set } \\
\text { yang } \\
\text { dapat } \\
\text { membant } \\
\text { u } \\
\text { administr } \\
\text { ator } \\
\text { mengam } \\
\text { ankan } \\
\text { server } \\
\text { web }\end{array}$ & $\begin{array}{l}\text { diperoleh } \\
\text { oleh } \\
\text { penyerang } \\
\text { dapat } \\
\text { mengakibat } \\
\text { kan } \\
\text { kerugian } \\
\text { besar bagi } \\
\text { konsumen } \\
\text { dan } \\
\text { perusahaan. }\end{array}$ & & $\begin{array}{l}\text { setelah } 15 \\
\text { kali } \\
\text { pengujian } \\
\text { menggunaka } \\
\text { n } 3 \text { Sistem } \\
\text { Operasi } \\
\text { perbedaan. }\end{array}$ \\
\hline 7. & $\begin{array}{l}\text { Penerapa } \\
\mathrm{n} \\
\text { Metode } \\
\text { ISSAF } \\
\text { dan } \\
\text { OWASP } \\
\text { versi } 4 \\
\text { Untuk } \\
\text { Uji } \\
\text { Kerentan } \\
\text { an Web } \\
\text { Server }\end{array}$ & $\begin{array}{l}\text { Dr. Raden } \\
\text { Teduh } \\
\text { Dirgahayu, } \\
\text { S.T., M.Sc., } \\
\text { Yudi } \\
\text { Prayudi, } \\
\text { S.Si., } \\
\text { M.Kom., Adi } \\
\text { Fajaryanto }\end{array}$ & $\begin{array}{l}\text { Jurnal } \\
\text { Ilmiah } \\
\text { NERO } \\
\text { Vol. } 1 \\
\text { No. } 3\end{array}$ & $\begin{array}{l}\text { pengujia } \\
\mathrm{n} \\
\text { terhadap } \\
\text { webserve } \\
\text { r IKIP } \\
\text { PGRI } \\
\text { menggun } \\
\text { akan } \\
\text { penetrati } \\
\text { on } \\
\text { testing, } \\
\text { agar } \\
\text { dapat } \\
\text { direkome } \\
\text { ndasikan } \\
\text { upaya } \\
\text { untuk } \\
\text { memini } \\
\text { malisir } \\
\text { tingkat } \\
\text { kerentan } \\
\text { an sistem } \\
\text { yang } \\
\text { ada. }\end{array}$ & $\begin{array}{l}\text { webserver } \\
\text { IKIP PGRI } \\
\text { Madiun, } \\
\text { sejak } \\
\text { pertama } \\
\text { webserver } \\
\text { online } \\
\text { sampai saat } \\
\text { ini } \\
\text { webserver } \\
\text { berhasil } \\
\text { dibobol } \\
\text { oleh hacker } \\
\text { beberapa } \\
\text { kali dalam } \\
\text { setahun dan } \\
\text { belum } \\
\text { pernah } \\
\text { dilakukan } \\
\text { penetrationt } \\
\text { est pada } \\
\text { webservern } \\
\text { ya. }\end{array}$ & $\begin{array}{l}\text { ISSAF } \\
\text { dan } \\
\text { OWAS } \\
\text { P }\end{array}$ & $\begin{array}{l}\text { Hasil } \\
\text { pengujian } \\
\text { dan analisa } \\
\text { dengan } \\
\text { metode } \\
\text { ISSAF } \\
\text { menunjukka } \\
\text { n bahwa } \\
\text { sistem web } \\
\text { server IKIP } \\
\text { PGRI } \\
\text { Madiun } \\
\text { masih dapat } \\
\text { ditembus } \\
\text { dan } \\
\text { mengambil } \\
\text { alih hak } \\
\text { akses } \\
\text { administrato } \\
\text { r, sedangkan } \\
\text { dengan } \\
\text { metode } \\
\text { OWASP } \\
\text { versi } 4 \\
\text { menunjukka } \\
\text { n bahwa } \\
\text { manajemen } \\
\text { otentifikasi, } \\
\text { otorisasi dan } \\
\text { manajemen } \\
\text { sesi } \\
\text { belum } \\
\text { diimplement } \\
\text { asikan }\end{array}$ \\
\hline
\end{tabular}




\begin{tabular}{|c|c|c|c|c|c|c|c|}
\hline & & & & & & & dengan baik. \\
\hline 8. & $\begin{array}{l}\text { Penerapa } \\
\mathrm{n} \\
\text { Pengujia } \\
\mathrm{n} \\
\text { Keaman } \\
\text { an Web } \\
\text { Server } \\
\text { Menggu } \\
\text { nakan } \\
\text { Metode } \\
\text { OWASP } \\
\text { versi } 4 \\
\text { (Studi } \\
\text { Kasus } \\
\text { Web } \\
\text { Server } \\
\text { Ujian } \\
\text { Online) }\end{array}$ & $\begin{array}{l}\text { Mohmmad } \\
\text { Muhsin, Adi } \\
\text { Fajaryanto }\end{array}$ & $\begin{array}{l}\text { Multitek } \\
\text { Indonesia } \\
\text { Vol. 9, } \\
\text { No. 1 Juni } \\
2015\end{array}$ & $\begin{array}{l}\text { menerap } \\
\text { kan } \\
\text { pengujia } \\
\mathrm{n} \\
\text { keamana } \\
\mathrm{n} \\
\text { aplikasi } \\
\text { Ujian } \\
\text { Online } \\
\text { menggun } \\
\text { akan } \\
\text { metode } \\
\text { OWASP } \\
\text { versi } 4 \\
\text { agar } \\
\text { dapat } \\
\text { diketahui } \\
\text { tingkat } \\
\text { kerentan } \\
\text { an yang } \\
\text { ada. }\end{array}$ & $\begin{array}{l}\text { Mengingat } \\
\text { pentingnya } \\
\text { data yang } \\
\text { tersimpan } \\
\text { maka perlu } \\
\text { diterapkan } \\
\text { pengujian } \\
\text { keamanan } \\
\text { dari aplikasi }\end{array}$ & $\begin{array}{l}\text { OWAS } \\
\text { P }\end{array}$ & $\begin{array}{l}\text { Hasil } \\
\text { pengujian } \\
\text { menggunaka } \\
\text { n OWASP } \\
\text { versi } 4 \\
\text { menunjukka } \\
\text { n bahwa } \\
\text { manajemen } \\
\text { otentifikasi, } \\
\text { otorisasi dan } \\
\text { manajemen } \\
\text { sesi belum } \\
\text { diimplement } \\
\text { asikan } \\
\text { dengan baik } \\
\text { sehingga } \\
\text { perlu } \\
\text { dilakukan } \\
\text { perbaikan } \\
\text { lebih lanjut } \\
\text { oleh pihak } \\
\text { stake holder } \\
\text { Fakultas } \\
\text { Teknik } \\
\text { Universitas } \\
\text { Muhammadi } \\
\text { yah } \\
\text { Ponorogo }\end{array}$ \\
\hline 9. & $\begin{array}{l}\text { An } \\
\text { integrate } \\
\mathrm{d} \\
\text { security } \\
\text { testing } \\
\text { framewo } \\
\text { rk for } \\
\text { Secure } \\
\text { Software } \\
\text { Develop } \\
\text { ment } \\
\text { Life } \\
\text { Cycle }\end{array}$ & $\begin{array}{l}\text { Yuan-Hsin } \\
\text { Tung, } \\
\text { Sheng-Chen } \\
\text { Lo, Jen-Feng } \\
\text { Shih, and } \\
\text { Hung-Fu Lin }\end{array}$ & $\begin{array}{l}\text { Asia- } \\
\text { Pacific } \\
\text { Network } \\
\text { Operation } \\
\text { s and } \\
\text { Managem } \\
\text { ent } \\
\text { Symposiu } \\
\text { m } \\
\text { (APNOM } \\
\text { S) }\end{array}$ & $\begin{array}{l}\text { kami } \\
\text { mengusu } \\
\text { lkan } \\
\text { framewo } \\
\text { rk } \\
\text { pengujia } \\
\text { n } \\
\text { keamana } \\
\text { n } \\
\text { terintegr } \\
\text { asi } \\
\text { untuk } \\
\text { siklus } \\
\text { hidup } \\
\text { pengemb } \\
\text { angan } \\
\text { perangka } \\
\text { t lunak } \\
\text { yang } \\
\text { aman. } \\
\text { Dalam }\end{array}$ & $\begin{array}{l}\text { Ratusan } \\
\text { kerentanan } \\
\text { dan cacat } \\
\text { keamanan } \\
\text { diungkapka } \\
\text { n oleh } \\
\text { peretas, } \\
\text { pengemban } \\
\text { g, dan } \\
\text { pengguna. }\end{array}$ & SSDLC & $\begin{array}{l}\text { Hasil } \\
\text { menunjukka } \\
\mathrm{n} \text { bahwa } \\
\text { sistem } \\
\text { prototipe } \\
\text { kami dapat } \\
\text { memberikan } \\
\text { kualitas dan } \\
\text { layanan } \\
\text { yang stabil. } \\
\text { Sistem } \\
\text { prototipe } \\
\text { menunjukka } \\
\text { n } \\
\text { bahwa } \\
\text { pendekatan } \\
\text { kami efisien } \\
\text { untuk } \\
\text { melakukan } \\
\text { masalah } \\
\text { keamanan di }\end{array}$ \\
\hline
\end{tabular}




\begin{tabular}{|c|c|c|c|c|c|c|c|}
\hline & & & & $\begin{array}{l}\text { framewo } \\
\text { rk usulan } \\
\text { kami, } \\
\text { kami } \\
\text { menerap } \\
\text { kan } \\
\text { kegiatan } \\
\text { keamana } \\
\text { n dan } \\
\text { praktik } \\
\text { SSDLC } \\
\text { untuk } \\
\text { menghas } \\
\text { ilkan } \\
\text { pedoman } \\
\text { keamana } \\
\text { n }\end{array}$ & & & $\begin{array}{l}\text { bawah } \\
\text { pengembang } \\
\text { an perangkat } \\
\text { lunak. } \\
\text { Dalam studi } \\
\text { selanjutnya, } \\
\text { kami akan } \\
\text { terus } \\
\text { menambahk } \\
\text { an fitur ke } \\
\text { kerangka } \\
\text { kerja kami } \\
\text { yang } \\
\text { diusulkan } \\
\text { untuk tujuan } \\
\text { peningkatan } \\
\text { keamanan } \\
\text { perangkat } \\
\text { lunak. }\end{array}$ \\
\hline $\begin{array}{l}1 \\
0 .\end{array}$ & $\begin{array}{l}\text { Secure } \\
\text { Coding } \\
\text { in } \\
\text { Software } \\
\text { Develop } \\
\text { ment }\end{array}$ & $\begin{array}{l}\text { Nor Harisah } \\
\text { Zainuddin, } \\
\text { Assoc.Prof.D } \\
\text { r.Normaziah } \\
\text { Abd Aziz }\end{array}$ & $\begin{array}{l}\text { Malaysian } \\
\text { Conferenc } \\
\text { e in } \\
\text { Software } \\
\text { Engineeri } \\
\text { ng } \\
\text { (MySEC) }\end{array}$ & $\begin{array}{l}\text { Paper ini } \\
\text { menyoro } \\
\text { ti } \\
\text { kerentan } \\
\text { an } \\
\text { perangka } \\
\text { t lunak } \\
\text { dan } \\
\text { pendekat } \\
\text { an untuk } \\
\text { mengatas } \\
\text { inya. } \\
\text { Selain } \\
\text { kesadara } \\
\text { n seperti } \\
\text { itu } \\
\text { yang } \\
\text { telah } \\
\text { berlangs } \\
\text { ung } \\
\text { selama } \\
\text { dekade } \\
\text { terakhir, } \\
\text { penelitia } \\
\text { n ini } \\
\text { mengusu } \\
\text { lkan alat } \\
\text { yang } \\
\text { dapat } \\
\text { meningk } \\
\text { atkan }\end{array}$ & $\begin{array}{l}\text { Seiring } \\
\text { dengan } \\
\text { meningkatn } \\
\text { ya jumlah } \\
\text { pengguna } \\
\text { dan aplikasi } \\
\text { tidak sah, } \\
\text { kerentanan } \\
\text { sistem } \\
\text { dapat } \\
\text { memperlak } \\
\text { ukan } \\
\text { individu } \\
\text { dan } \\
\text { organisasi. }\end{array}$ & $\begin{array}{l}\text { SDLC } \\
\text { and } \\
\text { OWAS } \\
\text { P }\end{array}$ & $\begin{array}{l}\text { Kesimpulan } \\
\text { nya, } \\
\text { keamanan } \\
\text { bukanlah } \\
\text { sesuatu yang } \\
\text { ada } \\
\text { ditujukan } \\
\text { pada akhir } \\
\text { pengembang } \\
\text { an perangkat } \\
\text { lunak atau } \\
\text { dimasukkan } \\
\text { fase tertentu } \\
\text { dari SDLC } \\
\text { tetapi perlu } \\
\text { diintegrasika } \\
\text { n } \\
\text { di seluruh } \\
\text { SDLC untuk } \\
\text { menghasilka } \\
\text { n perangkat } \\
\text { lunak yang } \\
\text { aman. Itu } \\
\text { pentingnya } \\
\text { keamanan } \\
\text { harus } \\
\text { dimasukkan } \\
\text { ke dalam } \\
\text { pikiran } \\
\text { pengembang } \\
\text { perangkat }\end{array}$ \\
\hline
\end{tabular}




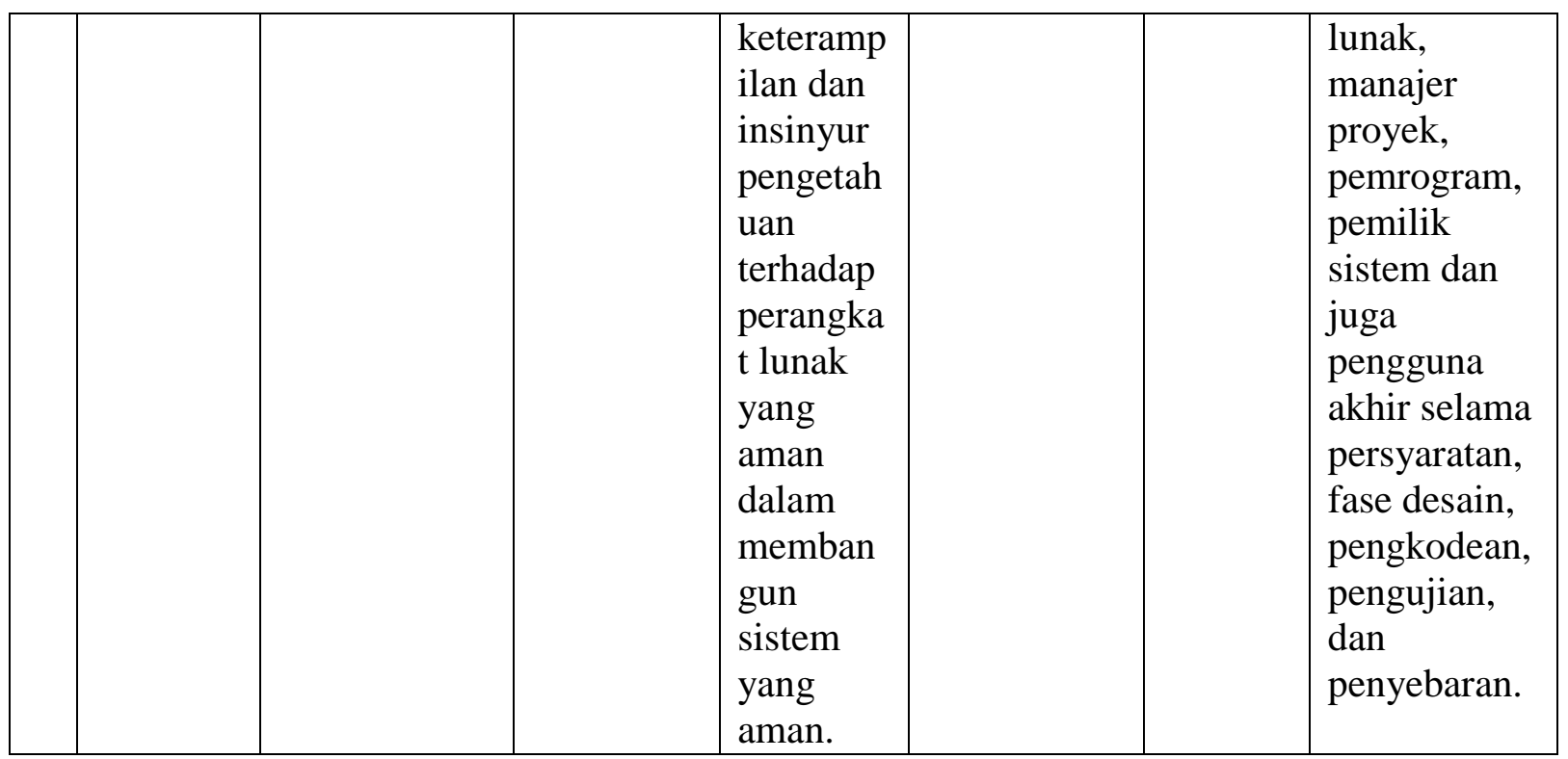

\section{RESEARCH METHOD}

\section{A. Systematic Literature Review}

Tinjauan literatur sistematis berarti laporan dari "pertanyaan yang dirumuskan dengan jelas yang menggunakan metode sistematis dan eksplisit untuk mengidentifikasi, memilih, dan menilai secara kritis penelitian yang relevan dan untuk mengumpulkan dan menganalisis data dari studi yang termasuk dalam ulasan" (Liberati et al., 2009; van Laar, van Deursen, van Dijk, \& de Haan, 2017). Penelitian literatur ini dibuat sesuai dengan Item Pelaporan Pilihan untuk Tinjauan Sistematis dan pedoman Analisis-Meta atau juga dikenal sebagai pedoman PRISMA untuk metode tinjauan literatur sistematis (van Laar et al., 2017). Urutan penelitian ini ditulis sesuai dengan Daftar Periksa PRISMA(Liberati et al., 2009). Metode ini dipilih, karena membantu mensintesis literatur akademik dengan cara yang akurat dan dapat diandalkan (van Laar et al., 2017).

Pendekatan PRISMA menyajikan daftar berbasis temuan dari 27 komponen dan diagram alir terdiri dari empat fase(Liberati et al., 2009). Daftar komponen melibatkan evaluasi reabilitas penelitian sebelumnya (van Laar et al., 2017). PRISMA tidak diusulkan sebagai teknik penilaian, tetapi PRISMA diusulkan untuk memastikan ketepatan dan kejelasan saat menulis makalah literatur sistematis. Daftar PRISMA dari 27 komponen dan diagram alir terdiri dari empat fase digunakan untuk melaporkan hasil (Liberati et al., 2009).

\section{B. Research Question}

Karena kebutuhan untuk mengevaluasi secara efektif kegunaan dari domain aplikasi spesifik, beberapa penulis telah mengembangkan studi untuk membangun faktor penentu keberhasilan dalam mengembangkan kinerja proyek sistem informasi. Dalam hal ini, membangun faktor-faktor itu penting untuk mengetahui pendekatan mana yang digunakan penulis untuk mengembangkan faktor-faktor keberhasilan kritis baru dalam mengembangkan proyek sistem informasi dan jika pendekatan yang digunakan memungkinkan menciptakan dan memvalidasi faktor-faktor keberhasilan kritis dalam mengembangkan proyek sistem informasi dengan benar (Quiñones \& Rusu, 2017).

Tinjauan literatur sistematis ini ditulis berdasarkan pengamatan pada faktor-faktor keberhasilan pengembangan sistem informasi. Studi ini perlu disesuaikan dengan baik di 
setiap organisasi yang proses utamanya berjalan pada pengembangan sistem informasi. Ketidakpedulian pengembangan sistem informasi akan menyebabkan kerugian pada proses bisnis. Karena itu, para peneliti dalam penelitian ini merasa sangat penting. Oleh karena itu, pertanyaan penelitian terbaik untuk tinjauan literatur sistematis ini adalah "Apakah FrameworkSSDLCdapat mengurangi kerentanan keamanan pada sistem perangkat lunak?"

\section{Study Selection Criteria}

Makalah yang dipilih harus memenuhi kriteria tinjauan literatur sistematis ini untuk menghasilkan hasil yang sesuai. Karena itu, kriteria inklusi harus mencakup:

1. Makalah yang merupakan makalah penelitian.

2. Makalah yang menjelaskan tentang framework-framework SSDLC dan tools yang digunakan.

3. Makalah yang menjelaskan tentang tinjauan literatur sistematis PRISMA.

4. Makalah yang diterbitkan dari 2014 hingga 2019.

5. Makalah yang ditulis dalam bahasa Inggris dan bahasa Indonesia.

6. Makalah yang diterbitkan di ScienceDirect, Scopus, JSTOR, IEEE, atau SpringerLink.

7. Makalah yang diterbitkan pada konferensi internasional dan jurnal internasional.

Kriteria pengecualian yang tidak memenuhi persyaratan meliputi:

1. Tesis yang tidak dipublikasikan.

2. Makalah yang tidak fokus terutama pada pengembangan sistem informasi.

\section{Data extraction}

Item data yang diekstraksi dari setiap artikel review termasuk: tinjauan literatur sistematis tentang faktor-faktor keberhasilan kritis dalam pengembangan sistem informasi menggunakan daftar periksa PRISMA; penulis penelitian; jurnal; Tanggal penerbitan; kondisi yang ditangani oleh setiap ulasan, dan intervensi diperiksa. Setiap item daftar periksa PRISMA dinilai memadai, tidak memadai, tidak dijelaskan, atau tidak berlaku [8].

Penelitian sebelumnya yang terlibat dalam penelitian literatur sistematis ini terkait dengan framework-framework SSDLC dan tools yang digunakan. Informasi diidentifikasi dan diekstraksi mengenai elemen-elemen berikut:

1. Penulis dan tahun makalah.

2. Domain yang diusulkan dalam framework-framework SSDLC dan tools yang digunakan.

\section{RESULT}

Strategi pencarian termasuk 16 paper kandidat dari tinjauan literatur sistematis ini. Hanya 8 paper yang dipilih dalam analisis akhir yang teks lengkapnya mengalami ekstraksi data karena terkait dengan studi tinjauan literatur sistematis ini. 8 makalah dikeluarkan karena artikel berada di luar ruang lingkup penelitian literatur ini.

\section{A. Study results}

Penelitian literatur ini mengamati alasan mengapa framework SSDLC aman digunakan dan dapat mengurangi kerentanan keamanan. Faktor penentu keberhasilan dikumpulkan dari penelitian sebelumnya yang ditunjukkan pada tabel di bawah ini.

\begin{tabular}{|c|c|c|}
\hline Penulis & Tools & $\begin{array}{r}\text { Hasil } \\
\end{array}$ \\
\hline $\begin{array}{l}\text { Robinson, Memen } \\
\text { Akbar, Muhammad Arif }\end{array}$ & OWASP & $\begin{array}{l}\text { SQL Injection Attack : Dari } 7 \text { jenis } \\
\text { serangan, } 6 \text { berhasil mengamankan }\end{array}$ \\
\hline
\end{tabular}




\begin{tabular}{|c|c|c|}
\hline \multirow[t]{4}{*}{ Fadhly Ridha } & & dan mendeteksi serangan. \\
\hline & & $\begin{array}{l}\text { SQLmap Exploitation : Dari } 3 \text { sistem } \\
\text { operasi yang diserang, } 3 \text { berhasil } \\
\text { mengamankan dan mendeteksi } \\
\text { serangan. }\end{array}$ \\
\hline & & $\begin{array}{l}\text { BeEF Exploitation : Dari } 3 \text { sistem } \\
\text { operasi yang diserang, } 3 \text { gagal } \\
\text { mengamankan dan mendeteksi } \\
\text { serangan. }\end{array}$ \\
\hline & & $\begin{array}{l}\text { XSSer Exploitation : Dari } 3 \text { sistem } \\
\text { operasi yang diserang, } 3 \text { berhasil } \\
\text { mengamankan dan mendeteksi } \\
\text { serangan. }\end{array}$ \\
\hline $\begin{array}{l}\text { Radek Fujdiak, Petr } \\
\text { Mlynek, Pavel Mrnustik, } \\
\text { Maros Barabas, Petr } \\
\text { Blazek, Filip Borcik, Jiri } \\
\text { Misurec. }\end{array}$ & $\mathrm{mSSDLC}$ & $\begin{array}{l}\text { Berkat analisis tahap awal melalui } \\
\text { mSSDLC dan manajemen } \\
\text { pendekatan tahap awal mendapatkan } \\
\text { informasi yang cukup untuk } \\
\text { resimulasi, yang memberikan } \\
\text { informasi yang cukup valid untuk } \\
\text { proses pengambilan keputusan dan } \\
\text { menghemat waktu serta biaya. }\end{array}$ \\
\hline $\begin{array}{ll}\text { Daniel Fischer, } & \text { Mehran } \\
\text { Sarkarati, } & \text { Mariella } \\
\text { Spada, } & \text { Thomas } \\
\text { Michelbach, } & \text { Wenzel } \\
\text { Urban, Christian } & \\
\text { Tueffers } & \end{array}$ & $\begin{array}{l}\text { Penggunaan } \text { SSDLC } \\
\text { framework untuk COSIF- } \\
\text { based web application } \\
\text { development }\end{array}$ & $\begin{array}{l}\text { Kerangka kerja keamanan aplikasi } \\
\text { untuk penyediaan sistem data misi } \\
\text { SOA yang mampu meningkatkan } \\
\text { secara signifikan ketahanan dan } \\
\text { keamanan aplikasi layanan web. At } \\
\text { the same time, the framework } \\
\text { provides a set of tools } \\
\text { and templates that aim at reducing } \\
\text { the effort related to the } \\
\text { additional steps, introduced in the } \\
\text { SSDLC. }\end{array}$ \\
\hline $\begin{array}{l}\text { Ade Kurniawan, Imam } \\
\text { Riadi, Ahmad Luthfi }\end{array}$ & OWASP & $\begin{array}{l}\text { berhasil mendeteksi, memfilter, } \\
\text { memblokir, dan memberi tahu } \\
\text { pengguna sehingga korban menjadi } \\
\text { lebih waspada jika pengguna } \\
\text { menjelajah bahwa telah ada muatan } \\
\text { yang dimilikinya } \\
\text { telah disuntikkan oleh penyerang ke } \\
\text { situs web dengan } \\
\text { bentuk skrip kait dari Cross Site } \\
\text { Scripting }\end{array}$ \\
\hline 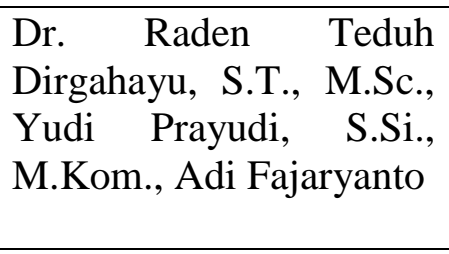 & ISSAF dan OWASP & $\begin{array}{l}\text { metode ISSAF menunjukkan bahwa } \\
\text { sistem web server IKIP } \\
\text { PGRI Madiun masih dapat ditembus } \\
\text { dan mengambil alih hak akses } \\
\text { administrator, }\end{array}$ \\
\hline
\end{tabular}




\begin{tabular}{|c|c|c|}
\hline & & $\begin{array}{l}\text { metode OWASP versi } 4 \\
\text { menunjukkan bahwa manajemen } \\
\text { otentifikasi, otorisasi dan manajemen } \\
\text { sesi } \\
\text { belum diimplementasikan dengan } \\
\text { baik. }\end{array}$ \\
\hline $\begin{array}{l}\text { Mohmmad Muhsin, Adi } \\
\text { Fajaryanto }\end{array}$ & OWASP & $\begin{array}{l}\text { Hasil pengujian menggunakan } \\
\text { OWASP versi } 4 \text { menunjukkan bahwa } \\
\text { manajemen otentifikasi, otorisasi dan } \\
\text { manajemen sesi belum } \\
\text { diimplementasikan dengan baik }\end{array}$ \\
\hline \multirow[t]{2}{*}{$\begin{array}{lr}\text { Robertus } & \text { Halomoan } \\
\text { Hutagalung, Lukito Edi } \\
\text { Nugroho, } \\
\text { Hidayat }\end{array}$} & \multirow[t]{2}{*}{ OWASP } & $\begin{array}{l}\text { celah Sql Injection terhadap } \\
\text { server.te.ugm.ac.id dapat di generate } \\
\text { dan menghasilkan penilaian } \\
\text { kemungkinan dengan angka } 6.375 \\
\text { dengan tingkat kemungkinan secara } \\
\text { keseluruhan adalah High dan dampak } \\
\text { teknis secara keseluruhan } \\
\text { menghasilkan nilai } 3.75 \text { yang berarti } \\
\text { tingkat dampak pada sisi teknis } \\
\text { adalah Medium, sedangkan dampak } \\
\text { bisnis secara keseluruhan } \\
\text { menghasilkan nilai } 1.75 \text { yang mana } \\
\text { berarti tingkat dampak pada sisi } \\
\text { bisnis adalah Low }\end{array}$ \\
\hline & & $\begin{array}{l}\text { celah Xss Injection terhadap } \\
\text { server.te.ugm.ac.id dapat di generate } \\
\text { dan menghasilkan penilaian } \\
\text { kemungkinan dengan angka } 6.25 \\
\text { dengan tingkat kemungkinan secara } \\
\text { keseluruhan adalah High dan dampak } \\
\text { teknis secara keseluruhan } \\
\text { menghasilkan nilai } 3.25 \text { yang berarti } \\
\text { tingkat dampak pada sisi teknis } \\
\text { adalah Medium, sedangkan dampak } \\
\text { bisnis secara keseluruhan } \\
\text { menghasilkan nilai } 1.75 \text { yang mana } \\
\text { berarti tingkat dampak pada sisi } \\
\text { teknis adalah Low }\end{array}$ \\
\hline $\begin{array}{l}\text { Yuan-Hsin Tung, Sheng- } \\
\text { Chen Lo, Jen-Feng Shih, } \\
\text { and Hung-Fu Lin }\end{array}$ & SSDLC & $\begin{array}{l}\text { Hasilnya menunjukkan bahwa sistem } \\
\text { prototipe kami dapat memberikan } \\
\text { layanan yang berkualitas dan stabil. }\end{array}$ \\
\hline
\end{tabular}

\section{CONCLUSION}

Kesimpulan dari penelitian ini adalah bahwasanya Framework-framework SSDLC dapat mengevaluasi kerentanan keamanan pada sistem perangkat lunak. Dengan demikian perancang/developer perangkat lunak dapat menerapkan secure coding agar sistem yang akan dibangun dapat lebih rentan dari ancaman penyerangan. 


\section{REFERENCES}

Fujdiak, R., Mlynek, P., Mrnustik, P., Barabas, M., Blazek, P., Borcik, F., \& Misurec, J. (2019). Managing the secure software development. 2019 10th IFIP International Conference on New Technologies, Mobility and Security, NTMS 2019 - Proceedings and Workshop, 1-4. https://doi.org/10.1109/NTMS.2019.8763845

Kurniawan, A., Riadi, I., \& Luthfi, A. (2017). Forensic analysis and prevent of cross site scripting in single victim attack using open web application security project (OWASP) framework. Journal of Theoretical and Applied Information Technology, 95(6), 13631371.

Liberati, A., Altman, D. G., Tetzlaff, J., Mulrow, C., Gøtzsche, P. C., Ioannidis, J. P. A., ... Moher, D. (2009). The PRISMA statement for reporting systematic reviews and metaanalyses of studies that evaluate healthcare interventions: explanation and elaboration. BMJ (Clinical Research Ed.), 339. https://doi.org/10.1136/bmj.b2700

Quiñones, D., \& Rusu, C. (2017). How to develop usability heuristics: A systematic literature review. Computer Standards and Interfaces, 53(September 2016), 89-122. https://doi.org/10.1016/j.csi.2017.03.009

Tung, Y. H., Lo, S. C., Shih, J. F., \& Lin, H. F. (2016). An integrated security testing framework for Secure Software Development Life Cycle. 18th Asia-Pacific Network Operations and Management Symposium, APNOMS 2016: Management of Softwarized Infrastructure - Proceedings. https://doi.org/10.1109/APNOMS.2016.7737238

van Laar, E., van Deursen, A. J. A. M., van Dijk, J. A. G. M., \& de Haan, J. (2017). The relation between 21 st-century skills and digital skills: A systematic literature review. Computers in Human Behavior, 72, 577-588. https://doi.org/10.1016/j.chb.2017.03.010

Pidgeon, T. E., Wellstead, G., Sagoo, H., Jafree, D. J., Fowler, A. J., \& Agha, R. A. (2016). An assessment of the compliance of systematic review articles published in craniofacial surgery with the PRISMA statement guidelines: A systematic review. Journal of Cranio-Maxillofacial Surgery, $\quad 44(10), \quad 1522-1530$. https://doi.org/10.1016/j.jcms.2016.07.018

Krishnamurthy, R., Meinel, M., Haupt, C., Schreiber, A., \& Mader, P. (2018). DLR secure software engineering. Proceedings - 2018 ACM/IEEE 1st International Workshop on Security Awareness from Design to Deployment, SEAD 2018, 49-50. https://doi.org/10.23919/SEAD.2018.8472854

Fischer, D., Sarkarati, M., Spada, M., Michelbach, T., Urban, W., \& Tueffers, C. (2011). An application security framework for SOA-based mission data systems. Proceedings - 4th IEEE International Conference on Space Mission Challenges for Information Technology, SMC-IT 2011, 53-60. https://doi.org/10.1109/SMC-IT.2011.22

Kurniawan, A., Riadi, I., \& Luthfi, A. (2017). Forensic analysis and prevent of cross site scripting in single victim attack using open web application security project (OWASP) framework. Journal of Theoretical and Applied Information Technology, 95(6), 13631371. 
Mada, U. G. (2017). Menentukan Dampak Resiko Keamanan Berbasis Pendekatan Owasp. Prosiding SNATIF, 477-484.

Akbar, M., Arif, M., Ridha, F., \& Scripting, A. C. S. (2018). INTERNATIONAL JOURNAL ON INFORMATICS VISUALIZATION SQL Injection and Cross Site Scripting Prevention Using OWASP Web Application Firewall. Journal on Informatics Visualization Sql, 2, 286-292.

Dirgahayu, T., Prayudi, Y., \& Fajaryanto, A. (2015). Penerapan Metode ISSAF dan OWASP versi 4 Untuk Uji Kerentanan Web Server. Jurnal Ilmiah NERO, 1(3), 190-197. Retrieved from http://nero.trunojoyo.ac.id/index.php/nero/article/download/29/27

M. Muhsin, A. Fajaryanto, "Penerapan Pengujian Keamanan Web Server Menggunakan Metode OWASP versi 4 (Studi Kasus Web Server Ujian Online)," Multitek Indonesia, Vol. 9, pp. 31-42, 2015.

Zenah, N. H. Z., \& Aziz, N. A. (2011). Secure coding in software development. 2011 5th Malaysian Conference in Software Engineering, MySEC 2011, 458-464. https://doi.org/10.1109/MySEC.2011.6140716

Ghozali, B., Kusrini, K., \& Sudarmawan, S. (2019). Mendeteksi Kerentanan Keamanan Aplikasi Website Menggunakan Metode Owasp (Open Web Application Security Project) Untuk Penilaian Risk Rating. Creative Information Technology Journal, 4(4), 264. https://doi.org/10.24076/citec.2017v4i4.119

Yu, H., Jones, N., Bullock, G., \& Yuan, X. Y. (2011). Teaching secure software engineering: Writing secure code. 2011 7th Central and Eastern European Software Engineering Conference, CEE-SECR 2011, 1-5. https://doi.org/10.1109/CEE-SECR.2011.6188473

Kao, T. C., Mao, C. H., Chang, C. Y., \& Chang, K. C. (2012). Cloud SSDLC: Cloud security governance deployment framework in secure system development life cycle. Proc. of the 11th IEEE Int. Conference on Trust, Security and Privacy in Computing and Communications, TrustCom-2012 - 11th IEEE Int. Conference on Ubiquitous Computing and Communications, IUCC-2012, 1143-1148. https://doi.org/10.1109/TrustCom.2012.106.

Tung, Y. H., Lo, S. C., Shih, J. F., \& Lin, H. F. (2016). An integrated security testing framework for Secure Software Development Life Cycle. 18th Asia-Pacific Network Operations and Management Symposium, APNOMS 2016: Management of Softwarized Infrastructure - Proceedings. https://doi.org/10.1109/APNOMS.2016.7737238

Yang, J., Lodgher, A., \& Lee, Y. (2019). Secure modules for undergraduate software engineering courses. Proceedings - Frontiers in Education Conference, FIE, 2018October, 1-5. https://doi.org/10.1109/FIE.2018.8658433 